unique biochemistry and mechanisms for conserving energy. The bulk of the book focuses on these issues. Mechanisms for production of methane from known substrates, the biosynthesis and role of coenzymes unique to the methanogens and anabolic reactions are all described. Following advances made in understanding the biochemistry of methanogenesis came detailed studies of energy conservation carried out principally in the laboratory of Gerhard Gottschalk. The chapter by him and colleagues summarizes present knowledge and unique features of energy conservation by methanogens but also presents a view on mechanisms still requiring confirmation.

The final chapter by John Reeve deals with the structure and organization of genes in methanogens. This aspect of methanogen genetics has made rapid progress in comparison to the development of efficient methods of gene transfer. The latter area is not included in Reeve's chapter although, as acknowledged in the editor's preface, gene transfer holds the key to rapid advances in many of the areas discussed throughout the book. Wolfe saw fit to end his 'historical overview' with the report of $P$. Schönheit that methanogens can now be grown under non-methanogenic conditions. This intriguing finding, taken together with the potential application of molecular genetic techniques, will mean that future editions of this book, excellent though it is, will need to accommodate much new information.

David Archer is at the Institute of Food Research, Norwich Research Park, Colney, Norwich NR4 TUA, UK.

\title{
Episode of human evolution
}

\section{Ian Tattersall}

The Origin of Modern Humans. By Roger Lewin. Scientific American Library/W. $H$. Freeman: 1993. Pp. 204. \$32.95, £18.95.

YET another book on modern human origins, currently the hottest topic in human evolution? Inevitably, yes. But with a difference. This one is by a single author, in contrast to the recent crop of edited volumes in which the usual pundits are trotted out at chapter length, in a remarkable variety of permutations and combinations. For Roger Lewin, a shrewd and seasoned journalistic observer of the palaeoanthropological scene, has taken it upon himself to present to the general reader a lavishly illustrated summary of the present state of play in this contentious field.

Actually, Lewin's book resembles the edited works to the extent that he has interviewed most of the aforementioned pundits, and quotes from many of them at some length. But despite his admirable attempts to present all sides of the argument, and his observer's reluctance to project his own sympathies too vigorously, Lewin makes no pretence of hiding these sympathies - which lie with those who believe that Homo sapiens originated in a single place, rather than in a worldwide process. Letting them out of the bag helps to give Lewin's book a focus that the edited volumes lack, and makes for an altogether more satisfying read.

To provide a context for his account of the continuing debate, Lewin starts right at the beginning. He succinctly reviews the history of discovery and analysis of the entire human fossil record, and the intrusion into its study of molecular systema- tics, functional anatomy, archaeology and so forth. He is particularly good at evoking the way in which theoretical expectations have, throughout, affected interpretation of the evidence. Appropriately, he dwells at greatest length on the Neanderthals who, apart from being perhaps our closest extinct relatives, are the archaic human species that was most un- ground' explanations that attempt to incorporate aspects of both. He does, however, devote an entire chapter to 'mitochondrial Eve'. Such separate treatment not only has the advantage of decoupling this contentious issue from the palaeontological underpinnings of the "single origin' view, but it also allows space for the most lucid general review of this complex topic I've seen.

The archaeological record shows clearly that the achievement of modern anatomy and of modern behaviour were not the same thing. Having dealt with anatomy, Lewin thus devotes the second half of his short book to the archaeological record and its interpretation. As he notes, recognizing 'modern' behaviour (whatever that is) from the archaeological traces of longvanished populations is a far from simple task. Archaeologists differ, indeed, as vociferously as palaeoanthropologists do. One might expect that, delving into the complexities of cave art and the origins of consciousness and language, Lewin would display the same sympathy with those who believe in a late and rapid acquisition of the unique human capacity as he does in earlier chapters with proponents of a single origin for anatomically modern humans. Instead, he remains more detached, and this detachment gives the second half of his book a more muted tone than the first - although it's nonetheless a very useful rendition of the complexities of the ongoing debate.

\section{IMAGE UNAVAILABLE FOR COPYRIGHT REASONS}

\section{Where do we go from here? From the film The Man Called Flintstone.}

arguably replaced by modern forms.

The background thus set, Lewin proceeds to contrast the two major competing viewpoints on modern human origins, and to summarize the evidence for each. Implicitly recognizing that the 'single origin' and 'multiregional continuity' models of modern human emergence are products of totally different and irreconcilable views of how the evolutionary process operates. he wastes little time on the 'middle-
Lewin has produced a readable and well organized account of the most important and most recent, yet most mysterious, episode in human evolution. It's an excellent introduction for the general reader, and many professionals will want it for the wealth of ideas aired in its pages.

Ian Tattersall is in the Department of Anthropology, American Museum of Natural History, New York, New York 10024, USA. 